\title{
UTILISASI PPK II BPJS KESEHATAN: ANALISIS PERBANDINGAN PERILAKU WARGA KOMPLEK PERUMAHAN DAN WARGA PERKAMPUNGAN DI DEPOK
}

Nia Murniati

Laboratorium Perumahsakitan Program Vokasi UI, niaboyhadi@yahoo.com

\author{
Diterima : 1 April 2015
}

Layak Terbit : 18 Juni 2015

\begin{abstract}
Abstrak
Kehadiran Badan Penyelenggara Jaminan Sosial (BPJS) Kesehatan sebenarnya bertujuan untuk memberikan jaminan agar peserta memperoleh manfaat pemeliharaan dan perlindungan dalam pemenuhan kebutuhan dasar kesehatan. Praktiknya, sebagian peserta sering mengeluhkan panjangnya proses birokrasi yang harus ditempuh untuk bisa memanfaatkan layanan tersebut, khususnya bagi pasien di Rumah Sakit (RS). Sistem manage care yang diterapkan BPJS mengharuskan pelayanan berjenjang melalui Penyedia Pelayanan Kesehatan (PPK) Tingkat 1 seperti puskesmas, klinik, atau dokter keluarga. Mengingat, RS bukan puskesmas besar yang bisa menerima semua pasien dengan berbagai bentuk jaminan kesehatan, maka peserta harus disaring dulu oleh layanan primer di PPK 1. Proses ideal yang diterapkan BPJS ini tentu saja memerlukan birokrasi panjang dan waktu yang tidak sebentar. Hal ini yang seringkali dirasa peserta BPJS terlalu bertele-tele sehingga membuat tidak sabar. Meskipun untuk kondisi pasien darurat, RS selaku PPK Tingkat 2 dapat menerima pasien langsung tanpa rujukan dari PPK 1, namun persepsi sehat sakit dan kondisi darurat seringkali tidak sepakat antara peserta BPJS dan RS. Hal inilah yang seringkali menimbulkan gap pelayanan BPJS Kesehatan sehingga menyebabkan ketidaknyamanan pada kedua belah pihak. Perbedaan persepsi yang berpotensi terhadap perubahan perilaku kesehatan peserta BPJS dalam memanfaatkan fasilitas kesehatan menjadi fokus utama dalam penelitian ini dengan mempertimbangkan letak geografis tempat tinggal berdasarkan komplek perumahan dan perkampungan. Penelitian dilakukan secara survey dengan alat bantu kuesioner sebagai pedoman wawancara. Subyek penelitian adalah penduduk Kota Depok dengan kriteria inklusi yang telah mendapatkan pelayanan BPJS Kesehatan di RS maksimal tiga bulan terakhir. Sampling dilakukan secara insidental selama satu minggu pada penduduk Kota Depok (11 Kecamatan). Hasil akhir dari penelitian ini diharapkan dapat menjadi masukan bagi BPJS Kesehatan dalam meningkatkan mutu pelayanan kesehatan kepada masyarakat.
\end{abstract}

Kata Kunci: BPJS, PPK II, Utilisasi.

\begin{abstract}
The presence of the Social Security Agency (BPJS) actually Health aims to provide a guarantee that participants benefited the maintenance and protection in fulfilling the basic needs of health. Practice, some participants often complain of the long bureaucratic process that must be taken in order to take advantage of these services, particularly for patients at the Hospital (RS). Manage system of care that is applied BPJS require tiered services through Health Care Providers (PPK) Level 1 with a health center, clinic or family doctor. Given, RS is not a big health center that accepts all patients with various forms of health insurance, the participant must be filtered out by primary care in PPK 1. The ideal process is applied BPJS This of course requires a lengthy bureaucracy and a long time. It is often felt to participants BPJS too wordy so make impatient. Although for emergency patient's condition, as the KDP RS Level 2 can accept patients directly without a referral from the KDP 1, but a healthy perception of pain and emergencies often disagree among participants BPJS and RS. This is what often leads to BPJS Health care gap, causing discomfort on both sides. Differences in
\end{abstract}


perception that have the potential to change health behavior BPJS participants in the health facilities be the main focus in this study taking into account the geographical location of residence based on housing estates and villages. Research conducted the survey with tools to guide the interview questionnaire. Subjects were residents of the city of Depok with inclusion criteria who have received health care at the hospital BPJS a maximum of three months. Sampling is done incidentally during one week in Depok City residents $(11$ districts). The final results of this study are expected to be input for BPJS Health in improving the quality of health services to the community.

Keywords: BPJS, 2nd Provider, Utilization.

\section{PENDAHULUAN}

Pertama kali diluncurkan pada 1 Januari 2014, Badan Penyelenggara Jaminan Sosial (BPJS) Kesehatan sebenarnya bertujuan untuk memberikan jaminan agar peserta memperoleh manfaat pemeliharaan dan perlindungan dalam pemenuhan kebutuhan dasar kesehatan. Praktiknya, sebagian peserta sering mengeluhkan panjangnya proses birokrasi yang harus ditempuh untuk bisa memanfaatkan layanan tersebut, khususnya bagi pasien di Rumah Sakit (RS).

Sistem manage care yang diterapkan BPJS mengharuskan pelayanan berjenjang melalui Penyedia Pelayanan Kesehatan (PPK) Tingkat 1 seperti puskesmas, klinik, atau dokter keluarga. Mengingat, RS bukan puskesmas besar yang bisa menerima semua pasien dengan berbagai bentuk jaminan kesehatan, maka peserta harus disaring dulu oleh layanan primer di PPK 1.

Proses ideal yang diterapkan BPJS ini tentu saja memerlukan birokrasi panjang dan waktu yang tidak sebentar. Hal ini yang seringkali dirasa peserta BPJS terlalu bertele-tele sehingga membuat tidak sabar. Meskipun untuk kondisi pasien darurat, RS selaku PPK Tingkat 2 dapat menerima pasien langsung tanpa rujukan dari PPK 1, namun persepsi dan perilaku sehat sakit serta kondisi darurat seringkali tidak sepakat antara peserta BPJS dan RS.

Perilaku inilah yang seringkali menimbulkan gap pelayanan BPJS Kesehatan sehingga menyebabkan ketidaknyamanan pada kedua belah pihak.

Perilaku kesehatan peserta BPJS dalam memanfaatkan fasilitas kesehatan dapat dikaji menurut Socio Behavioural Models Andersen yang telah dielaborasi oleh Kroeger, 3 variabel yang berhubungan dengan penggunaan fasilitas penyembuhan seperti karakteristik individu, persepsi terhadap penyakit serta karakteristik dari pelayanan kesehatan itu sendiri. Sementara fasilitas kesehatan yang dapat dimanfaatkan berupa pengobatan sendiri (S), pertolongan medis (M) dan pertolongan Non medis (N). Pada model Kroeger terlihat bahwa reinforcing factor atau faktor penguat dari model Green tidak secara eksplisit ditampakkan tetapi Kroeger menonjolkan variabel dari 
karakteristik dan persepsi terhadap penyakit dimana model ini mirip dari model $H B M$.

Memahami fenomena sosial dalam memetakan masalah perilaku pemanfaatan fasilitas kesehatan dalam hal pengobatan medis maupun non medis harus melihat fungsinya terhadap keseluruhan sistem. Ada tiga alasan dasar dalam struktur sosial masyarakat. Pertama posisi tertentu lebih menyenangkan untuk diduduki daripada posisi yang lainnya. Kedua, posisi tertentu lebih penting untuk menjaga kelangsungan hidup masyarakat daripada posisi lainnya. Ketiga, posisi sosial yang berbeda memerlukan bakat dan kemampuan yang berbeda pula.

Penerapan kajian Pertukaran sosial dan Pilihan Rasional adalah bahwa masyarakat akan menimbang untung-rugi, nilai kepuasan yang diperoleh, ikatan emosional apa yang dipertukarkan. Dalam konteks ini dianalogikan hubungan antara pasien dengan si pengobat (medis dan non medis). Apalagi dalam warga perkampungan yang masih sederhana, adanya ikatan emosional sesama mereka seringkali mendasari proses pertukaran ini. Dalam konteks ini, teori pertukaran untuk mengkaji perbedaan masyarakat dalam penggunaan layanan kesehatan.

\section{METODOLOGI}

Penelitian ini menganalisis perilaku pemanfaatan fasilitas kesehatan yang dilakukan warga komplek perumahan dan warga perkampungan dengan perspektif pertukaran sosial dan Health Belief Model. Menganalisis hubungan antara karakteristik keluarga dalam hal: kondisi ekonomi, pendidikan kepala keluarga, sikap terhadap pemeliharaan kesehatan, kekhawatiran terhadap penyakit dan dukungan lingkungan sosial dengan perilaku pemanfaatan fasilitas kesehatan. Juga menganalisis hubungan antara karakteristik individu penderita dalam hal: umur, jenis kelamin, jenis penyakit dan daya tahan tubuh dengan perilaku pemanfaatan fasilitas kesehatan.

Landasan teori untuk memahami perilaku masyarakat dalam memanfaatkan fasilitas kesehatan melalui kajian Pertukaran Sosial (Exchange Theory), Health Belief Model (HBM), Socio Behavioural Models Kroeger. Dalam Health Belief Model dinyatakan terdapat komponen yang mempengaruhi seseorang mengambil tindakan yaitu adanya ancaman, manfaat hasil, kepekaan yang dirasakan dan penghalang serta kepercayaan untuk melaksanakan tindakan.

Hipotesis penelitian ini adalah: Ada perbedaan perilaku warga komplek perumahan dan warga perkampungan dilihat dari karakteristik keluarga (kondisi ekonomi, pendidikan kepala keluarga, sikap terhadap pemeliharaan kesehatan, kekhawatiran keluarga terhadap penyakit, dukungan lingkungan sosial), dan ada hubungan antara variabel dilihat dari karakteristik individu penderita (umur, jenis kelamin, jenis penyakit, kondisi daya tahan tubuh ) dengan perilaku pemanfaatan fasilitas kesehatan.

Rancangan penelitian ini adalah kuantitatif dengan metode survei. 
Tabel 1.

Karakteristik responden

\begin{tabular}{|c|c|c|}
\hline Karakteristik & Jumlah & $(\%)$ \\
\hline \multicolumn{3}{|l|}{ Kecamatan } \\
\hline Beji & 10 & 9,1 \\
\hline Cimanggis & 10 & 9,1 \\
\hline Sukmajaya & 10 & 9,1 \\
\hline Limo & 10 & 9,1 \\
\hline Sawangan & 10 & 9,1 \\
\hline Pancoran Mas & 10 & 9,1 \\
\hline Cipayung & 10 & 9,1 \\
\hline Cilodong & 10 & 9,1 \\
\hline Cinere & 10 & 9,1 \\
\hline Tapos & 10 & 9,1 \\
\hline Bojong Sari & 10 & 9,1 \\
\hline \multicolumn{3}{|c|}{ Status Tempat Tinggal } \\
\hline $\begin{array}{l}\text { Warga Komplek } \\
\text { Perumahan }\end{array}$ & 55 & 50,0 \\
\hline $\begin{array}{l}\text { Warga } \\
\text { Perkampungan }\end{array}$ & 55 & 50,0 \\
\hline \multicolumn{3}{|l|}{ Umur } \\
\hline$<35$ tahun & 21 & 19,1 \\
\hline $35-50$ tahun & 56 & 50,9 \\
\hline$>50-65$ tahun & 27 & 24,5 \\
\hline$>65$ tahun & 6 & 5,5 \\
\hline \multicolumn{3}{|l|}{ Jenis Kelamin } \\
\hline Laki-laki & 26 & 23,6 \\
\hline Perempuan & 84 & 76,4 \\
\hline \multicolumn{3}{|l|}{ Status pernikahan } \\
\hline Menikah & 97 & 88,2 \\
\hline Pernah menikah & 8 & 7,3 \\
\hline Tidak menikah & 5 & 4,5 \\
\hline \multicolumn{3}{|l|}{ Jenis pekerjaan KK } \\
\hline Tidak Bekerja & 51 & 46,4 \\
\hline PNS & 9 & 8,2 \\
\hline Pegawai Swasta & 17 & 15,5 \\
\hline TNI/POLRI & 4 & 3,6 \\
\hline Buruh & 8 & 7,3 \\
\hline Wirausaha & 21 & 19,1 \\
\hline \multicolumn{3}{|l|}{ Pendidikan KK } \\
\hline SD & 8 & 7,3 \\
\hline SMP & 11 & 10,0 \\
\hline SMA & 43 & 39,1 \\
\hline Diploma & 25 & 22,7 \\
\hline Sarjana/Pasca & 23 & 20,9 \\
\hline \multicolumn{3}{|l|}{$\begin{array}{l}\text { Pengeluaran Rumah } \\
\text { Tangga per Bulan }\end{array}$} \\
\hline Kurang dari 1 juta & 7 & 6,4 \\
\hline $1-2$ juta & 28 & 25,5 \\
\hline $2-5$ juta & 53 & 48,2 \\
\hline $5-10$ juta & 22 & 20,0 \\
\hline
\end{tabular}

Populasinya adalah seluruh warga komplek perumahan dan warga perkampungan di
Depok yang pernah menggunakan fasilitas pelayanan kesehatan dengan kartu BPJS. Pengambilan responden dilakukan dengan teknik simple random sampling. Selanjutnya, data dari 110 responden yang didapatkan dari penghitungan dianalisis secara deskriptif dengan uji $\mathrm{T}$ pada tingkat kepercayaan sebesar $95 \%$.

\section{HASIL DAN PEMBAHASAN}

Karakteristik responden menurut kecamatan, status tempat tinggal, umur, jenis kelamin, status pernikahan, jenis pekerjaan KK, pendidikan KK dan pengeluaran RT

Berdasarkan tabel 1 dapat ditarik kesimpulan bahwa responden tersebar merata menurut kecamatan di Depok sebanyak 10 orang $(9,1 \%)$

Responden tersebar merata menurut status tempat tinggalnya yaitu kampung dan komplek sebanyak 55 orang $(50,0 \%)$

Sebagian besar responden berumur $35-50$ tahun sebanyak 56 orang $(50,9 \%)$ dan sebagian kecil responden berada pada kelompok umur lebih dari 65 tahun sebanyak 6 orang $(5,5 \%)$

Sebagian besar responden berjenis kelamin perempuan sebanyak 84 orang $(76,4 \%)$ dan sebagian kecil responden berjenis kelamin laki-laki sebanyak 26 orang (23,6\%)

Sebagian besar responden yang sudah menikah sebanyak 97 orang (88,2\%) dan sebagian kecil responden yang tidak menikah sebanyak 5 orang $(4,5 \%)$

Sebagian besar responden tidak bekerja sebanyak 51 orang $(46,4 \%)$ dan sebagian kecil responden bekerja sebagai TNI/POLRI 
sebanyak 4 orang $(3,6 \%)$

Sebagian besar responden berpendidikan SMA sebanyak 43 orang $(39,1 \%)$ dan sebagian kecil responden berpendidikan SD sebanyak 8 $\operatorname{orang}(7,3 \%)$

responden menggunakan PPK II adalah diantara range 3,13 sampai dengan range 3,65 .

Tabel 2.

Kemudahan menggunakan PPKII, Perilaku Pemeliharaan Kesehatan, Perilaku Pencarian Pelayanan Kesehatan, dan Perilaku Kesehatan Lingkungan

\begin{tabular}{|l|l|l|l|l|l|l|l|}
\hline \multicolumn{1}{|l|}{ Variabel } & Mean & SE & Med & Skw & SD & $\begin{array}{l}\text { Min- } \\
\text { Mak }\end{array}$ & $\begin{array}{l}\text { 95\% } \\
\text { CI }\end{array}$ \\
\hline $\begin{array}{l}\text { Kemudahan } \\
\text { menggunakan } \\
\text { PPK II }\end{array}$ & 3,39 & 0,230 & 4,0 & - & 1,375 & $1-5$ & $\begin{array}{l}3,13- \\
3,65\end{array}$ \\
\hline $\begin{array}{l}\text { Perilaku } \\
\begin{array}{l}\text { Pemeliharaan } \\
\text { Kesehatan }\end{array}\end{array}$ & 3,6727 & 0,230 & 3,5 & - & 0,86586 & $\begin{array}{l}1,5- \\
5\end{array}$ & $\begin{array}{l}3,5091 \\
- \\
3,8364\end{array}$ \\
\hline $\begin{array}{l}\text { Perilaku } \\
\text { Pencarian } \\
\begin{array}{l}\text { Pelayanan } \\
\text { Kesehatan }\end{array}\end{array}$ & 2,6250 & 0,230 & 2,5 & 0,944 & 0,88096 & $\begin{array}{l}1,25 \\
-5\end{array}$ & $\begin{array}{l}2,4585 \\
- \\
2,7915\end{array}$ \\
\hline $\begin{array}{l}\text { Perilaku } \\
\text { Kesehatan } \\
\text { Lingkungan }\end{array}$ & 4,35 & 0,230 & 4,625 & - & 0,72251 & $\begin{array}{l}2,5- \\
5\end{array}$ & $\begin{array}{l}4,2135 \\
- \\
4,4865\end{array}$ \\
\hline
\end{tabular}

Sebagian besar responden mempunyai pengeluaran rumah tangga per bulan $2-5$ juta sebanyak 53 orang $(48,2 \%)$ dan sebagian kecil responden rata-rata pengeluaran rumah tangga per bulan kurang dari 1 juta sebanyak 7 orang $(6,4 \%)$

Berdasarkan tabel 2 dapat diperoleh gambaran rata-rata kemudahan responden menggunakan PPK II adalah pada range 3,39 (95\% CI : 3,13 - 3,65), median pada range 4,0 dengan standar deviasi pada range 1,375. Kemudahan responden menggunakan PPK II terkecil pada range 1 dan kemudahan menggunakan PPK II terbesar pada range 5. Dari hasil estimasi interval dapat disimpulkan bahwa 95\% yakin bahwa rata-rata kemudahan
Gambaran rata-rata perilaku pemeliharaan kesehatan responden adalah pada range 3,6727 (95\% CI : 3,5091 - 3,8364), median pada range 3,5 dengan standar deviasi pada range 0,86586. Perilaku pemeliharaan kesehatan terkecil pada range 1,5 dan perilaku pemeliharaan kesehatan terbesar pada range 5. Dari hasil estimasi interval dapat disimpulkan bahwa 95\% yakin bahwa ratarata perilaku pemeliharaan kesehatan responden adalah diantara range 3,5091 sampai dengan range 3,8364 .

Gambaran rata-rata perilaku pencarian pelayanan kesehatan responden adalah pada range 2,6250 (95\% CI : 2,4585 - 2,7915), median pada range 2,5 dengan standar deviasi pada range 0,88096 . Perilaku pencarian 
pelayanan kesehatan terkecil pada range 1,25 dan perilaku pencarian pelayanan kesehatan terbesar pada range 5. Dari hasil estimasi interval dapat disimpulkan bahwa $95 \%$ yakin bahwa rata-rata perilaku pencarian pelayanan kesehatan responden adalah diantara range 2,4585 sampai deng

an range 2,7915 .
Berdasarkan tabel 4 dapat dilihat hubungan antara perilaku pemeliharaan kesehatan responden dengan kemudahan menggunakan PPK II menunjukkan hubungan yang lemah $(\mathrm{R}=0,122)$ dan berpola positif artinya semakin tinggi perilaku pemeliharaan kesehatan responden maka semakin mudah dalam menggunakan PPK II.

Tabel 3.

Distribusi Rata-Rata Persepsi Kemudahan Mengunakan PPK II Menurut Status Tempat Tinggal Responden

\begin{tabular}{|l|l|l|l|l|l|}
\hline $\begin{array}{l}\text { Status } \\
\text { Tempat } \\
\text { Tinggal }\end{array}$ & Mean & SD & SE & P value & $\mathbf{n}$ \\
\hline $\begin{array}{l}\text { Warga } \\
\text { Komplek }\end{array}$ & 3,15 & 1,471 & 0,198 & 0,061 & 55 \\
\cline { 1 - 3 } $\begin{array}{l}\text { Warga } \\
\text { Kampung }\end{array}$ & 3,64 & 1,238 & 0,167 & & 55 \\
\hline
\end{tabular}

Tabel 4.

Analisis Korelasi dan Regresi Perilaku Pemeliharaan Kesehatan, Perilaku Pencarian Pelayanan Kesehatan, Perilaku Kesehatan Lingkungan dengan Kemudahan Menggunakan PPK II

\begin{tabular}{|c|c|c|c|c|}
\hline Variabel & $\mathbf{R}$ & $\mathbf{R}^{2}$ & $\begin{array}{l}\text { Persamaan } \\
\text { Garis }\end{array}$ & $\begin{array}{l}P \\
\text { Value }\end{array}$ \\
\hline $\begin{array}{l}\text { Perilaku } \\
\text { Pemeliharaan } \\
\text { Kesehatan }\end{array}$ & 0,122 & 0,015 & $\begin{array}{l}\mathrm{KP}=2,680 \\
+\quad 0,194 \\
(\mathrm{PK})\end{array}$ & 0,205 \\
\hline $\begin{array}{l}\text { Perilaku } \\
\text { Pencarian } \\
\text { Pelayanan } \\
\text { Kesehatan }\end{array}$ & $\begin{array}{l}- \\
0,096\end{array}$ & 0,009 & $\begin{array}{l}\mathrm{KP}=3,783 \\
+\quad-0,149 \\
(\mathrm{PP})\end{array}$ & 0,321 \\
\hline $\begin{array}{l}\text { Perilaku } \\
\text { Kesehatan } \\
\text { Lingkungan }\end{array}$ & 0,138 & 0,019 & $\begin{array}{l}\mathrm{KP}=2,248 \\
+\quad 0,263 \\
(\mathrm{KL})\end{array}$ & 0,150 \\
\hline
\end{tabular}


Setiap satu peningkatan perilaku pemeliharaan kesehatan responden akan dapat meningkatkan 0,194 range kemudahan menggunakan PPK II. Namun, variabel perilaku pemeliharaan kesehatan hanya dapat menjelaskan $1,5 \%$ variasi pada variabel kemudahan menggunakan PPK II. Dari hasil uji statistik korelasi dan regresi didapatkan tidak ada hubungan yang signifikan antara perilaku pemeliharaan kesehatan responden dengan kemudahan menggunakan PPK II (P value $=0,205)$

Hubungan antara perilaku pencarian pelayanan kesehatan responden dengan kemudahan menggunakan PPK II menunjukkan hubungan yang lemah ( $\mathrm{R}=$ o,096) dan berpola negatif artinya semakin tinggi perilaku pencarian pelayanan kesehatan responden maka semakin sulit dalam menggunakan PPK II, setiap satu peningkatan perilaku pencarian pelayanan kesehatan responden akan dapat menurunkan o,149 range kemudahan menggunakan PPK II. Namun, variabel perilaku pencarian pelayanan kesehatan hanya dapat menjelaskan 0,9\% variasi pada variabel kemudahan menggunakan PPK II. Dari hasil uji statistik korelasi dan regresi didapatkan tidak ada hubungan yang signifikan antara perilaku pencarian pelayanan kesehatan responden dengan kemudahan menggunakan PPK II (P value $=0,321)$.

Hubungan antara perilaku kesehatan lingkungan responden dengan kemudahan menggunakan PPK II menunjukkan hubungan yang lemah $(\mathrm{R}=0,138)$ dan berpola positif artinya semakin tinggi perilaku kesehatan lingkungan responden maka semakin mudah dalam menggunakan PPK II, setiap satu peningkatan perilaku kesehatan lingkungan responden akan dapat meningkatkan 0,263 range kemudahan menggunakan PPK II. Namun, variabel perilaku kesehatan lingkungan hanya dapat menjelaskan $1,9 \%$ variasi pada variabel kemudahan menggunakan PPK II. Dari hasil uji statistik korelasi dan regresi didapatkan tidak ada hubungan yang signifikan antara perilaku kesehatan lingkungan responden dengan kemudahan menggunakan PPK II (P value $=0,150)$.

\section{PENUTUP}

\section{Simpulan}

Berdasarkan hasil penelitian, responden tersebar merata di 11 kecamatan di Depok dan tersebar merata menurut status tempat tinggalnya yaitu kampung dan komplek. Responden sebagian besar berumur 35 sampai dengan 50 tahun dan berjenis kelamin perempuan. Sebagian besar responden sudah menikah, tidak memiliki pekerjaan, dan mempunyai pendidikan SMA. Rata-rata pengeluaran rumah tangga per bulan responden yaitu 2 sampai dengan 5 juta.

Gambaran rata-rata kemudahan responden menggunakan PPK II adalah pada range 3,13 sampai dengan range 3,65. Gambaran ratarata perilaku pemeliharaan kesehatan responden adalah diantara range 3,5091 sampai dengan range 3,8364. Gambaran ratarata perilaku pencarian pelayanan kesehatan responden adalah diantara range 2,4585 sampai dengan range 2,7915. Gambaran rata- 
rata perilaku kesehatan lingkungan responden adalah diantara range 4,2135 sampai dengan range 4,4865 .

Dari hasil uji statistik T-test Independen dapat disimpulkan bahwa tidak ada perbedaan yang signifikan rata-rata persepsi kemudahan menggunakan PPK II antara warga yang tinggal di komplek dengan warga yang tinggal di kampung.

Dari hasil uji statistik korelasi dan regresi dapat disimpulkan bahwa tidak ada hubungan yang signifikan antara perilaku pemeliharaan kesehatan responden dengan kemudahan menggunakan PPK II, tidak ada hubungan yang signifikan antara perilaku pencarian pelayanan kesehatan responden dengan kemudahan menggunakan PPK II, dan tidak ada hubungan yang signifikan antara perilaku kesehatan lingkungan responden dengan kemudahan menggunakan PPK II.

\section{Saran}

Dalam meningkatkan derajat kesehatan masyarakat Indonesia, peranan BPJS sangat membantu masyarakat khususnya masyarakat menengah kebawah yang tidak mempunyai asuransi kesehatan. Dengan adanya BPJS ini peserta mengharapkan mendapatkan pelayanan kesehatan yang lebih baik meski ada kalanya tidak sesuai dengan kenyataannya. Dalam wawancara langsung selama penelitian, terungkap bahwa peserta yang menggunakan BPJS cenderung mendapatkan pelayanan yang tidak sesuai dengan harapan. Perawatan atau pengobatan yang dilakukan rumah sakit seringkali terbentur faktor pembiayaan kesehatan yang tidak cukup oleh BPJS, sehingga terjadi sikap terpinggirkan untuk pelayanan peserta yang menggunakan BPJS. Namun ada juga beberapa rumah sakit yang sangat terbuka dalam melayani pasien BPJS. Oleh karena itu, dalam kasus seperti ini sangat diperlukan penelitian lebih lanjut untuk mengungkap utilisasi PPK II BPJS

Gambaran rata-rata perilaku kesehatan lingkungan responden adalah pada range 4,35 (95\% CI : 4,2135 - 4,4865), median pada range 4,625 dengan standar deviasi pada range 0,72251 . Perilaku kesehatan lingkungan terkecil pada range 2,5 dan perilaku kesehatan lingkungan terbesar pada range 5. Dari hasil estimasi interval dapat disimpulkan bahwa 95\% yakin bahwa rata-rata perilaku kesehatan lingkungan responden adalah diantara range 4,2135 sampai dengan range 4,4865 


\section{DAFTAR PUSTAKA}

Anderson, R.M. (1999) Revisiting the Behavioral Model and Access to Medical Care: Does it Matter? J Health Soc Behavior, 36: $1-10$.

Azwar S. (2011). Sikap Manusia: Teori dan Pengukurannya. Yogyakarta: Pustaka Pelajar

Green, Lawrence W., Marchel W Kreuter. (1999) Health Promoting Planning an Educational and Environmental Aproach. Second Edition. Mayfield Publishing Company: Mountain View.

Judge TA, Bono JE (2001), Relationship of Core Self Evaluation Traits-Self Esteem, Generalized Self Efficacy, Locus of Controll and Emotional Stability-eith Job Statisfaction and Job Performance: a Meta Analysis, Journal of Applied Psychology, Vol. 86, No. 1, 80 - 92.

Lohrmann et al (2008), a Complementary Ecological Model of The Coordinated School Health Program, Public Health Report, Vol. 123.

Notoatmodjo, Soekidjo. (2010). Ilmu Perilaku Kesehatan. Jakarta : Rineka Cipta.

Undang-undang Nomor 40 Tahun 2004

Undang-undang Nomor 24 Tahun 2011 